\title{
Changes to Irradiation Conditions of VVER-1000 Surveillance Specimens Resulting from Fuel Assemblies with Greater Fuel Height
}

Pavel Panferov, Viacheslav Kochkin a , Dmitry Erak, Denis Makhotin, Alexandr Reshetnikov, and Andrey Timofeev

NRC “Kurchatov Institute”, 123182, 1 Kurchatov sq., Moscow, Russia

\begin{abstract}
The goal of the work was to obtain experimental data on the influence of newtype fuel assemblies with higher fuel rods on the irradiation conditions of surveillance specimens installed on the baffle of VVER-1000. For this purpose, two surveillance sets with container assemblies of the same design irradiated in reactors with different fuel assemblies in the core were investigated. Measurements of neutron dosimeters from these sets and retrospective measurements of ${ }^{54} \mathrm{Mn}$ activity accumulated in each irradiated specimen allow a detailed distribution of the fast neutron flux in the containers to be obtained. Neutron calculations have been done using 3D discrete ordinate code KATRIN. On the basis of the obtained results, a change of the lead factor due to newtype fuel assemblies was evaluated for all types of VVER-1000 container assemblies.
\end{abstract}

\section{Introduction}

VVER-1000 reactors are equipped with surveillance specimens which are irradiated in container assemblies (CA). Each container assembly contains one or several specimen containers and has one or two levels. Container assemblies are located on the baffle above the upper boundary of the core. Therefore, the fast neutron flux on surveillance specimens depends strongly on the distance between the upper fuel boundary and the specimen containers. Figure 1 shows CA locations in the reactor. As can be seen, there are two pairs of symmetrical positions: L1, L5 and L2, L4. Position L3 is the farthest from fuel assemblies and hence, specimens in this position are irradiated with the lowest flux. The fast neutron flux in positions L1 and L5 is approximately two times higher than that in position L3.

According to Russian normative requirements, irradiation conditions for surveillance specimen are limited by several parameters one of which is the Lead Factor (LF). LF defines as the ratio of the fast neutron fluence accrued by the specimens to the corresponding maximum fluence accrued by the inner surface of the Reactor Pressure Vessel (RPV). This ratio must be within "5" [1].

The Program of Increasing the Nominal Power and Fuel Cycle Duration for VVER-1000 Reactors is currently being implemented in Russia. In the framework of this Program, fuel assemblies of a new

\footnotetext{
${ }^{a}$ Corresponding author: slv_k@mail.ru
}

This is an Open Access article distributed under the terms of the Creative Commons Attribution License 2.0, which permits unrestricted use, distribution, and reproduction in any medium, provided the original work is properly cited. 

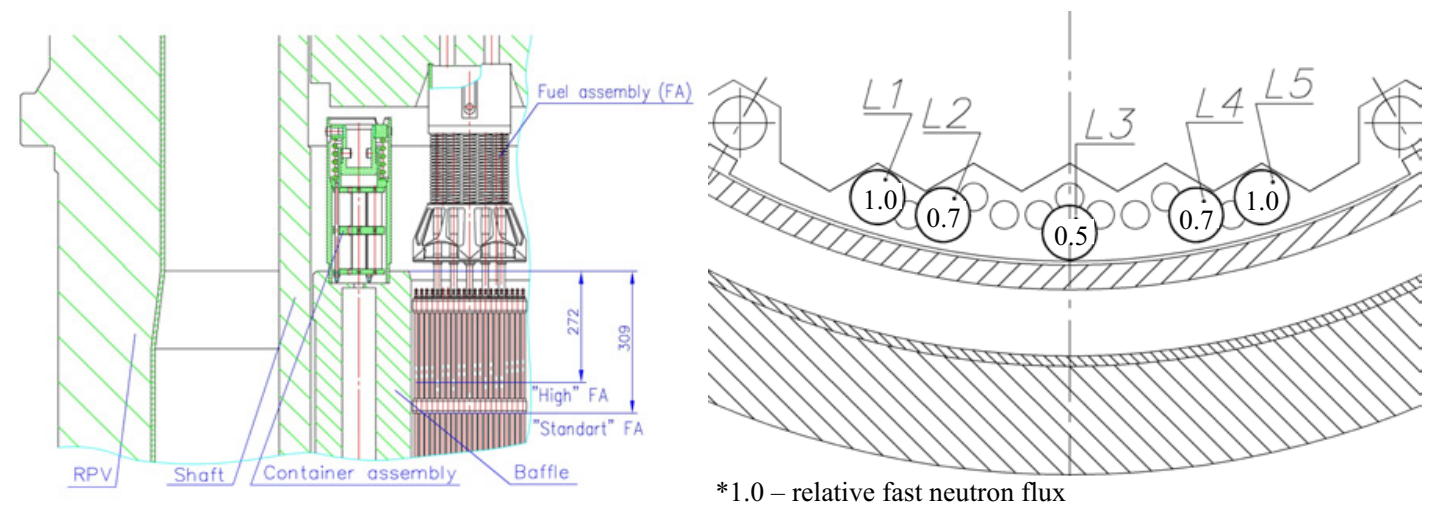

Figure 1. Container assembly on the baffle, left - axial view, right - azimuthal view.

type with higher fuel rods (which contain more fuel) are being installed in the core. At the same time, low leakage core configuration is being implemented. Preliminary calculations show that reducing the distance between specimens and the upper boundary of the core resulting from fuel assemblies of the new type could significantly increase the fast neutron flux in specimen containers located on the baffle. Conversely, implementation of a low leakage core configuration would decrease the fast neutron flux on the RPV. The coupled effect of these factors results in a significant increase of LF.

Conditions of surveillance specimens irradiation in VVER-1000 with standard fuel assemblies are fairly well characterized $[2,3]$. But there are no experimental data on irradiation conditions of specimens irradiated in a reactor with fuel assemblies of the new type.

The effect of variation of the type of fuel assemblies on the irradiation conditions of surveillance specimens has been studied through a comparison of dosimetry results obtained from two identical surveillance specimens sets. One of them (Set 1L) was irradiated in a reactor with standard fuel assemblies in the core, and the other one (Set 6L) was irradiated in a reactor with "high" fuel assemblies. Measurements of neutron dosimeters from these sets and retrospective measurements of ${ }^{54} \mathrm{Mn}$ activity accumulated in each irradiated specimen allow a detailed distribution of the fast neutron flux in the specimen containers to be obtained. The experimental investigations were combined with calculations of the fast neutron flux in container assemblies and on the inner surface of RPV.

\section{Design of Investigated Container Assemblies}

Below a comparison is made between the dosimetry results of the two surveillance sets irradiated in VVER-1000 reactors with different fuel assemblies in the core. Set 1L was irradiated in a reactor with standard fuel assemblies. Set $6 \mathrm{~L}$ is the first unloaded and investigated surveillance set which was irradiated in a reactor with "high" fuel assemblies in the core. Container assemblies from both sets have the same design and differ only in the disposition of specimens and neutron dosimetry capsules inside the containers. A scheme of the container assembly is shown in Fig. 2.

Four container assemblies from Set 1L have been irradiated in positions L1, L2 and L4, L5 (Fig. 1). Set $6 \mathrm{~L}$ consists of 2 assemblies irradiated in positions L4 and L5.

The arrangement of specimens and neutron dosimetry capsules in specimen containers are given in Fig. 3. There are 3 neutron dosimetry capsules in containers 1L4, 1L5 and 4 neutron dosimetry capsules in containers $1 \mathrm{~L} 1,1 \mathrm{~L} 2,6 \mathrm{~L} 4$, and 6L5. Each neutron dosimetry capsule contains iron and niobium foils for fast neutron fluence evaluation, but some of the $\mathrm{Nb}$ dosimeters were destroyed under irradiation and their remains were lost during unpacking of the capsules. 


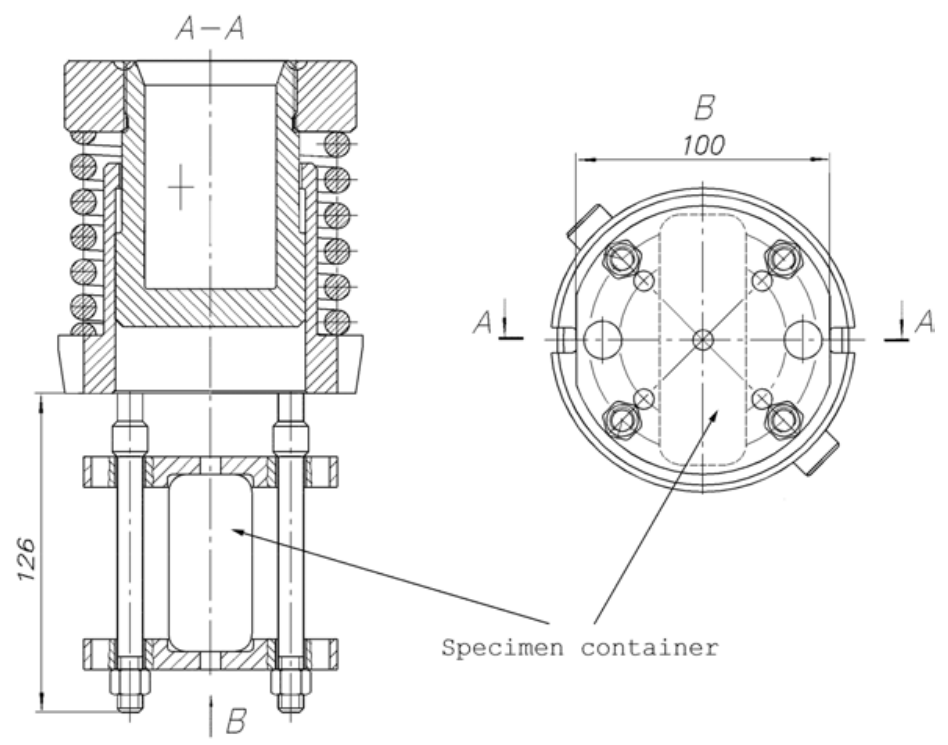

Figure 2. Container assembly scheme. Left - side view, right - top view.

Set 1L

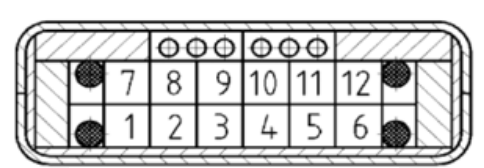

Containers L1 and L2

(Top view)

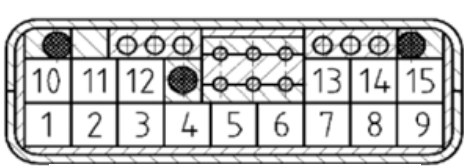

Containers L4 and L5 (Top view)

Set $6 \mathrm{~L}$

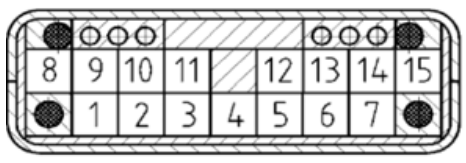

Container L4

(Top view)

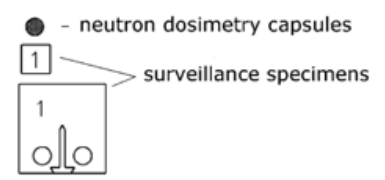

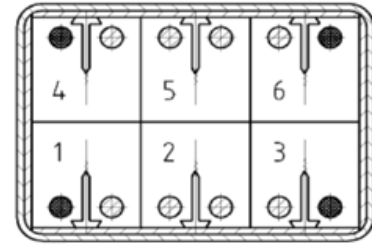

Container L5

(Front view)

Figure 3. Arrangement of neutron dosimetry capsules and specimens in containers.

\section{Measurements and Calculation Procedures}

The activities of ${ }^{54} \mathrm{Mn}$ and ${ }^{60} \mathrm{Co}$ in neutron dosimeters were measured using a gamma-spectrometry system which consists of a HPGe ORTEC GEM 35 detector with ORTEC Dspec-jr 2.0 analyzer. For the purpose of the count rate optimization, the gamma-spectrometry system has a sample holder with a variable distance between the detector surface and the sample. Calibration was made with ${ }^{54} \mathrm{Mn}$, 


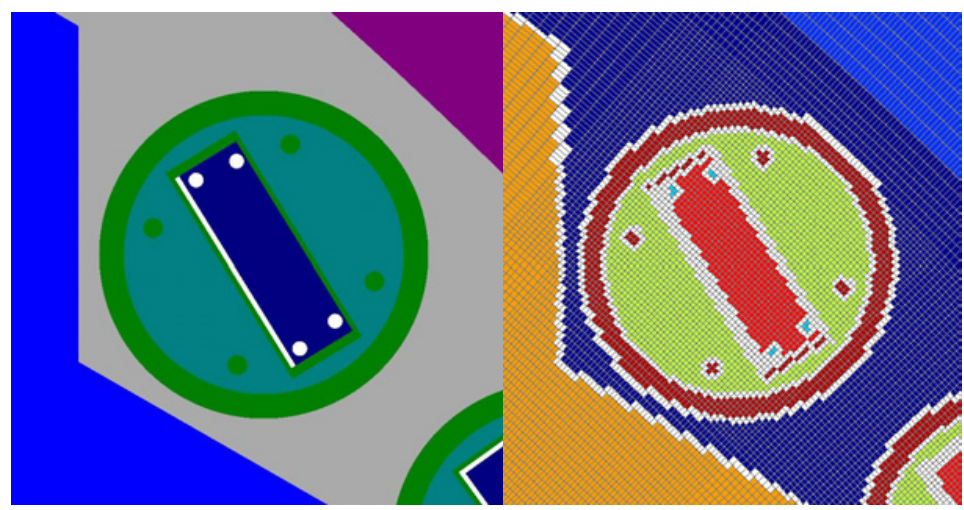

Figure 4. Fragments of the geometry model with CA. Left - combinatorial geometry, right - grid approximation (cells with additional mixtures are shown by white color).

${ }^{60} \mathrm{Co},{ }^{137} \mathrm{Cs},{ }^{152} \mathrm{Eu}$ gamma-sources from a set of OSGI reference gamma-sources. The error of measured activities was evaluated to be $2 \%$ ( 1 sigma).

A deposit preparation technique was used for ${ }^{93 \mathrm{~m}} \mathrm{Nb}$ activity measurements. Pure niobium foils were dissolved in $\mathrm{HF}$ with a drop of nitric acid $\left(\mathrm{HNO}_{3}\right)$. Then thin deposits were prepared from the obtained solutions. Measurements of ${ }^{94} \mathrm{Nb}$ activity for each deposit and dosimeters were carried out to determine the $\mathrm{Nb}$ mass on the deposit. X-ray spectra from ${ }^{93 \mathrm{~m}} \mathrm{Nb}$ were measured using a $\mathrm{Si}(\mathrm{Li})$ detector with an ORTEC Dspec-jr 2.0 analyzer. The detector was calibrated with X-ray reference sources and with a ${ }^{93 \mathrm{~m}} \mathrm{Nb}$ secondary reference source. Besides, duplicating ${ }^{93 \mathrm{~m}} \mathrm{Nb}$ activity measurements have been taken with the LSC technique. The ${ }^{93 \mathrm{~m}} \mathrm{Nb}$ activities obtained by both methods are in agreement within (2-3)\%. The error of the measured activities was evaluated to be $3 \%$ (1 sigma).

The fast neutron flux distribution in containers with surveillance specimens were investigated with "retrospective" dosimetry measurements of ${ }^{54} \mathrm{Mn}$ activity in each irradiated specimen. Relative ${ }^{54} \mathrm{Mn}$ activity in specimens was measured in a hot cell equipped with a collimation slit and a gammaspectrometry system. Later on, pieces of the metal were taken from several specimens for absolute ${ }^{54} \mathrm{Mn}$ activity measurements. Activity values of ${ }^{54} \mathrm{Mn}$ obtained from measurements of surveillance specimen material and those for iron dosimeters are in good agreement, the difference being about $2 \%$. These data were used to evaluate the actual orientation of the assemblies with respect to the core center.

Three-dimension $(\mathrm{R}-\Theta-\mathrm{Z})$ neutron transport computations were carried out in the $\mathrm{P}_{3} \mathrm{~S}_{16}$ approximation of the discrete ordinates method using the KATRIN-2.5 [5-10] code with 47-groups nuclear data library BGL-1000 based on the ENDF-B/VI data.

The KATRIN code package contains a ConDat converter which can also be used as a preprocessor. ConDat allows a user to produce a geometrical model description by a combinatorial geometry method and to convert a combinatorial problem geometry form to a "bit-mapped" one and to generate the problem geometry file. For the cells containing several materials, additional mixtures have been created. The algorithm known as a "Volume Fraction" method provides the mass balance maintenance in every cell of the grid. It allows one to represent accurately the reactor geometry in calculation models regardless of grid parameters.

Computations have been done using a pin-by-pin source distribution in the core. The neutron source was obtained directly from a 3D pin-by-pin burn-up distribution in the core taking into account the dependence of the neutron yield and energy per fission on fuel enrichment and a burn-up fraction. Computations of burn up increments have been done with codes regularly used in design and operational computations of VVER-1000 reactors (BIPR 7A and PERMAK-A). The grid approximation of the neutron source was made with a specially developed software package that took into account the 


\begin{tabular}{|c|c|}
\hline $\mathrm{ND}$ & $6 \mathrm{~L} 5$ \\
\hline $\mathrm{Fe}$ & 0.90 \\
\hline $\mathrm{Nb}$ & 0.98 \\
\hline
\end{tabular}$\quad$\begin{tabular}{|c|c|}
\hline $\mathrm{ND}$ & $6 \mathrm{~L} 5$ \\
\hline $\mathrm{Fe}$ & 0.90 \\
\hline $\mathrm{Nb}$ & 1.02 \\
\hline
\end{tabular}

\begin{tabular}{|c|c|c|c|c|c|c|}
\hline ND & 6L4 & & & & ND & 6L4 \\
\hline $\mathrm{Fe}$ & 0.86 & & & & $\mathrm{Fe}$ & 0.84 \\
\hline \multirow[t]{3}{*}{$\mathrm{Nb}$} & - & \multirow{2}{*}{$\begin{array}{l}0 \\
4\end{array}$} & \multirow{2}{*}{$\begin{array}{c}0 \\
5\end{array}$} & \multirow{2}{*}{$\begin{array}{c}9 \\
6\end{array}$} & $\mathrm{Nb}$ & 0.98 \\
\hline & & & & & & \\
\hline & & & & & & \\
\hline ND & 6L4 & - & $\oplus \|$ & 0] & ND & 6L4 \\
\hline $\mathrm{Fe}$ & 0.92 & & & & $\mathrm{Fe}$ & 0.86 \\
\hline $\mathrm{Nb}$ & 1.05 & & & & $\mathrm{Nb}$ & 1.00 \\
\hline
\end{tabular}

Figure 5. Comparison of Calculated and Experimental Dosimeter Activities (C/E) in Assemblies 6L4 and 6L5 of Set 6L.

\begin{tabular}{|c|c|c|c|c|c|c|}
\hline ND & 1L1 & 1L2 & & ND & 1L1 & 1L2 \\
\hline $\mathrm{Fe}$ & 1.07 & 1.08 & & $\mathrm{Fe}$ & 1.07 & 1.08 \\
\hline $\mathrm{Nb}$ & 1.23 & 1.13 & & $\mathrm{Nb}$ & 1.20 & 1.19 \\
\hline \multicolumn{7}{|c|}{\begin{tabular}{|l|l|l|l|l|l|l|l|l|}
$\mathbf{a}$ & 7 & 8 & 9 & 10 & 11 & 12 & \\
$\mathbf{a}$ & 1 & 2 & 3 & 4 & 5 & 6 \\
\end{tabular}} \\
\hline ND & 1L1 & 1L2 & & ND & 1L1 & 1L2 \\
\hline $\mathrm{Fe}$ & 1.05 & 1.07 & & $\mathrm{Fe}$ & 1.07 & 1.07 \\
\hline $\mathrm{Nb}$ & 1.26 & 1.15 & & $\mathrm{Nb}$ & 1.18 & - \\
\hline
\end{tabular}

\begin{tabular}{|c|c|c|c|c|c|c|}
\hline ND & 1L4 & 1L5 & & ND & 1L4 & 1L5 \\
\hline $\mathrm{Fe}$ & 1.09 & 1.08 & & $\mathrm{Fe}$ & 1.12 & 1.12 \\
\hline $\mathrm{Nb}$ & - & 1.26 & & $\mathrm{Nb}$ & 1.19 & 1.24 \\
\hline \multicolumn{7}{|c|}{ 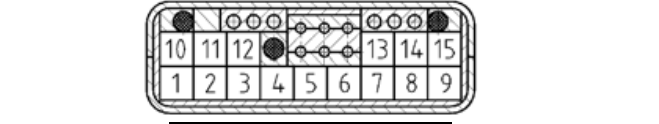 } \\
\hline & & ND & 1L4 & 1L5 & & \\
\hline & & $\mathrm{Fe}$ & 1.11 & 1.11 & & \\
\hline & & $\mathrm{Nb}$ & 1.22 & 1.25 & & \\
\hline
\end{tabular}

Figure 6. Comparison of Calculated and Experimental Dosimeter Activities (C/E) in Assemblies 1L1, 1L2 and 1L4, 1L5 of Set 1L.

contribution of each pin in the grid cell. One cell contained about 1-3 fuel pins. The spectrum of ${ }^{235} \mathrm{U}$ fission neutrons from the BGL-1000 library was taken as a source energy spectrum. Materials of the fuel assemblies in the core were homogenized.

Our comparison of primary calculated activities of neutron dosimeters and ${ }^{54} \mathrm{Mn}$ in specimens with corresponding measured activities shows that the actual orientation of CA relative to the core center differs from the design orientation. A set of calculations with different CA orientations to the core has been done to clarify the actual orientations of CA. The orientation of each CA relative to the core was evaluated from the ratio of measured to calculated ${ }^{54} \mathrm{Mn}$ activity in specimens using the least-square method.

\section{Results of Measurements and Calculations}

The comparison of calculated and measured dosimeter activities $(\mathrm{C} / \mathrm{E})$ in the containers of surveillance sets $6 \mathrm{~L}$ and $1 \mathrm{~L}$ is shown in Figs. 5, 6.

The relative distribution of measured and calculated activities of neutron dosimeters and surveillance specimens in all containers of Set $1 \mathrm{~L}$ and Set $6 \mathrm{~L}$ are in good agreement. The comparison of C/E values shows that the difference between calculated and experimental absolute ${ }^{54} \mathrm{Mn}$ activity is also acceptable being within $\pm 15 \%$. The average $\mathrm{C} / \mathrm{E}$ values for Set $1 \mathrm{~L}$ and Set $6 \mathrm{~L}$ are about 1.10 and 0.88 , respectively.

More appreciable discrepancies are observable in case of niobium dosimeters from Set $1 \mathrm{~L}$ and the averaged $\mathrm{C} / \mathrm{E}$ value here is about 1.23. The calculated and experimental activities of $\mathrm{Nb}$ dosimeters from Set $6 \mathrm{~L}$ are in excellent agreement and the $\mathrm{C} / \mathrm{E}$ value is about 0.99 . 
Table 1. Measured and Calculated ratios of ${ }^{54} \mathrm{Fe}(\mathrm{n}, \mathrm{p})^{54} \mathrm{Mn}$ and ${ }^{93} \mathrm{Nb}\left(\mathrm{n}, \mathrm{n}^{\prime}\right){ }^{93 \mathrm{~m}} \mathrm{Nb}$ reaction rates $\left(\mathrm{RR}_{\mathrm{Nb}} / \mathrm{RR}_{\mathrm{Fe}}\right)$.

\begin{tabular}{|c|c|c|c|c|c|c|c|c|}
\hline \multirow{2}{*}{ Set } & \multicolumn{2}{|c|}{ L1 Position } & \multicolumn{2}{|c|}{ L2 Position } & \multicolumn{2}{c|}{ L4 Position } & \multicolumn{2}{c|}{ L5 Position } \\
\cline { 2 - 9 } & calc & exp. & calc & exp. & calc & exp. & calc & exp. \\
\hline 1L & 1.93 & 1.69 & 1.86 & 1.73 & 1.91 & 1.77 & 1.91 & 1.68 \\
\hline 6L & - & - & - & - & 1.92 & 1.66 & 1.70 & 1.54 \\
\hline
\end{tabular}

Table 2. Neutron flux $(E>0.5 \mathrm{MeV})$ in containers of surveillance Set $1 \mathrm{~L}$ and Set $6 \mathrm{~L}$ (averaged over specimens in container).

\begin{tabular}{|c|c|c|}
\hline \multirow{2}{*}{ Set } & \multicolumn{2}{|c|}{ Averaged Fast neutrons flux $\phi_{>0,5} \times 10^{14} \mathrm{~m}^{-2} \mathrm{~s}^{-1}$} \\
\cline { 2 - 3 } & L1 (L5) Position & L2 (L4) Position \\
\hline 1L & 6.28 & 4.99 \\
\hline 6L & 11.7 & 8.31 \\
\hline
\end{tabular}

A detailed analysis of the ratios of ${ }^{54} \mathrm{Fe}(\mathrm{n}, \mathrm{p}){ }^{54} \mathrm{Mn}$ and ${ }^{93} \mathrm{Nb}\left(\mathrm{n}, \mathrm{n}^{\prime}\right)^{93 \mathrm{~m}} \mathrm{Nb}$ reaction rates $\left(\mathrm{RR}_{\mathrm{Nb}} / \mathrm{RR}_{\mathrm{Fe}}\right)$ shows that there is a systematic discrepancy between experimental and calculated data. The calculated and experimental $R R_{\mathrm{Nb}} / \mathrm{RR}_{\mathrm{Fe}}$ values are given in Table 1 . The calculated $\mathrm{RR}_{\mathrm{Nb}} / \mathrm{RR}_{\mathrm{Fe}}$ ratio in both $1 \mathrm{~L}$ and $6 \mathrm{~L}$ sets is about $12 \%$ higher than the experimental value. The most probable reason for the observed discrepancies is simplified homogenization of the fuel assembly geometry in the calculation model. It should be noted that the upper parts of a standard fuel assembly and a "high" fuel assembly are significantly different. Therefore, the homogenization effect for the upper parts of the fuel assemblies could be different in case of $1 \mathrm{~L}$ and $6 \mathrm{~L}$ sets. In order to improve the results, we intend to make a detailed 3-dimensional modeling of the fuel assembly geometry and materials.

Resulting from the above mentioned discrepancies between the measured and calculated activities of neutron dosimeters, the calculated fast neutron flux values in the specimen containers were corrected to the experimental data in accordance with Russian normative requirements [1]. Table 2 gives the neutron fluxes $(\mathrm{E}>0.5 \mathrm{MeV})$ obtained in the specimen containers irradiated in the reactor with standard fuel assemblies and with "high" fuel assemblies in the core.

The analysis shows that the use of fuel assemblies of the new type with higher fuel rods results in about a 1.8-fold increase in the fast neutron flux in containers with surveillance specimens. This value could be used for assessment of a LF change in VVER-1000 container assemblies of a different design due to "high" fuel assemblies.

\section{Estimation of LF Changes for Container Assemblies of a Different Design}

Container assemblies installed on the baffles in different VVER-1000 units may have a different design: e.g., the number of levels and the design of specimen containers. The design differences bring about the variation of the distance from the specimen center to the fuel upper bound in the core for various CA. These variations in turn cause differences in the fast neutrons flux in containers with specimens.

At present, there are several types of CA which are installed on the baffle of different VVER-1000 reactors:

a. Two-level assembly with six cylindrical containers on a level and its One-level (upper) modification (Fig. 7 (a-1,a-2));

b. Two-level assemblies with one rectangular container on a level and its One-level (lower) modification (Fig. 7 (b-1,b-2));

c. One-level assembly with a rectangular container where the container axial position is between the first and second levels of a type "b" assembly (Fig. 2).

The influence of new type fuel assemblies on the surveillance specimen irradiation conditions has been exemplified above by the investigation of container assemblies of type "c". 


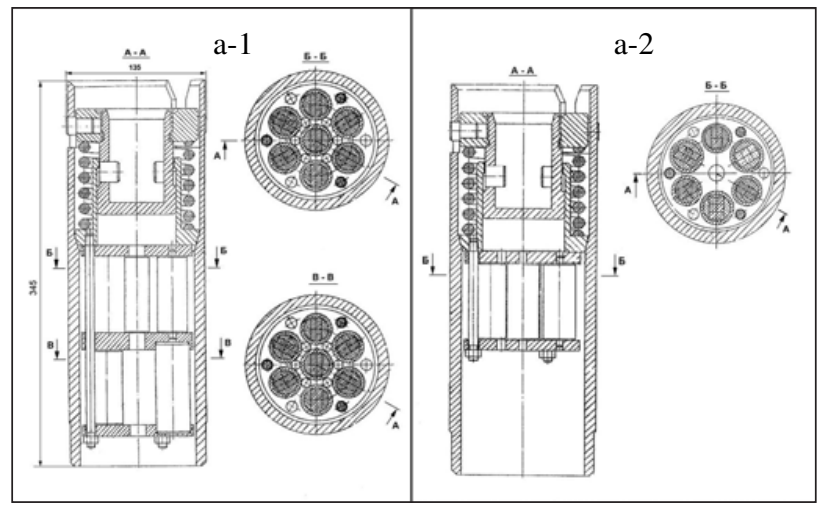

b-1

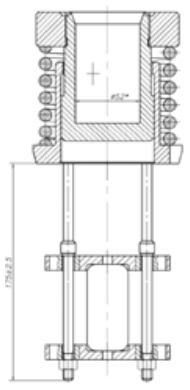

b-2

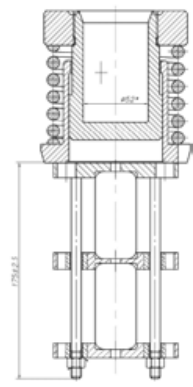

Figure 7. Schemes of container assemblies of different types.

Table 3. Estimated lead factors for CA of the different design irradiated in VVER-1000.

\begin{tabular}{|c|c|c|c|c|c|}
\hline \multirow{2}{*}{ CA type } & \multirow{2}{*}{ CA Level } & \multicolumn{4}{|c|}{ Lead Factor (averaged over level) } \\
\cline { 3 - 6 } & & standard fuel assemblies & "high" fuel assemblies \\
\cline { 3 - 6 } & L1 and L5 & L2 and L4 & L1 and L5 & L2 and L4 \\
\hline $\begin{array}{c}\text { Assembly with } \\
\text { cylindrical containers (a) }\end{array}$ & Upper level & 1.3 & 1.0 & 4.0 & 3.0 \\
\cline { 3 - 6 } & Lower level & 3.5 & 2.6 & 11 & 8.0 \\
\hline $\begin{array}{c}\text { Two-level assembly with } \\
\text { rectangular containers (b) }\end{array}$ & Lower level & 2.5 & 2.2 & 7.8 & 6.9 \\
\hline $\begin{array}{c}\text { One level assembly with } \\
\text { rectangular container (c) }\end{array}$ & - & 1.6 & 1.2 & 5.0 & 3.6 \\
\hline
\end{tabular}

The irradiation conditions of specimens in CA with cylindrical containers in VVER-1000 with standard fuel assemblies and with low leakage core loadings were studied in detail earlier in [2-4]. The design of this type of CA leads to very inhomogeneous irradiation of specimens. The neutron flux gradient in assemblies with a rectangular container depends strongly on the container orientation with respect to the core. For example, no significant neutron flux gradient was found in the containers of Set $6 \mathrm{~L}$ but the neutron flux more than doubles in the containers of Set 1L. With the view of general estimation of the influence of new-type fuel assemblies on the LF in different types of CA, it is reasonable to consider neutron fluxes averaged over all specimens at the CA level.

LF distribution in CA with cylindrical containers in VVER-1000 with standard fuel assemblies were estimated on the basis of surveillance dosimetry data and RPV neutron calculations validated by ex-vessel measurements in papers [2,3]. Lead Factors for assemblies with rectangular containers in the reactor with standard fuel assemblies has also been evaluated in the present paper.

The analysis of the data in Table 2 shows that fuel assemblies of the new type with higher fuel rods cause a nearly 1.8-fold increase in the fast neutron flux in containers with surveillance specimens. This value was used for assessment of a LF change in VVER-1000 CA of different design due to "high" fuel assemblies. Appropriate calculations of the neutron flux on the inner surface of RPV have been made for typical core loadings envisaged by the Program of Increasing the Nominal Power and Duration of a Fuel Cycle for VVER-1000.

The data presented in Table 3 shows a comparison of estimated lead factors for CA of different design irradiated in VVER-1000 with standard fuel assemblies and with "high" fuel assemblies.

As seen from Table 3, fuel assemblies of the new type in the presence of low-leakage core loadings lead to an increase of Lead Factor by approximately 3 times, and for some CA, the average LF exceeded " 5 ". 


\section{Conclusions}

Detailed experimental and calculation investigations of two VVER-1000 surveillance sets irradiated with different fuel assemblies in the core showed that fuel assemblies of the new type with higher fuel rods cause a nearly 1.8-fold increase in the fast neutron flux on the surveillance specimens. At the same time, application of a low leakage core configuration causes a decrease in the fast neutron flux on RPV approximately by 1.6 times. The said effects result in the triple increase of the ratio of the fast neutron flux $(E>0.5)$ on samples to the maximum fast neutron flux on the RPV. For some types of container assemblies, this ratio became significantly higher than " 5 ".

The surveillance sets which remain still not unloaded from VVER-1000 reactors were irradiated most of the time with standard fuel assemblies in the core. After the new-type fuel assemblies have been installed into the reactor core, the LF value begins to increase and even a rough estimation shows that it may exceed the limiting value after several companies.

Thus, in order to obey the regulations, it is necessary to control the parameters for each surveillance set with regard to both the fluence accrued in the course of irradiation with standard fuel assemblies in the core, and the fluence accrued after the implementation of the new fuel assemblies.

It should be noted that these factors were left out on the modernization of the VVER-1000 surveillance program [3] and the results obtained in this study led to its revision. Some activities, such as the installation of metrological assemblies with extended neutron dosimeter sets and regular monitoring of the neutron flux at the outer surface of the reactor vessel, must be included in the modernization program to control the Lead Factor.

\section{References}

[1] Regulations for the Control of Mechanical Properties of Operating VVER-1000 Reactor Pressure Vessels by the Surveillance Specimens Testing Results, 1.3.2.01.0061-2009, Rosenergoatom (in Russian)

[2] Zaritsky S.M., Borodin A.V., Brodkin E.B., Vikhrov V.I., Egorov A.L., Erak D.Yu., Kochkin V.N. "Dosimetry of the Experimental Surveillance Assemblies of WWER-1000 Balakovo Unit 1." In: Reactor Dosimetry in the $21^{\text {st }}$ Century. Proceedings of the $11^{\text {th }}$ International Symposium on Reactor Dosimetry. Brussels, Belgium, 18-23 August 2002. Eds Jan Wagemans, Hamid Aït Abderrahim, Pierre D’hondt, Charles De Raedt. World Scientific, 2003, pp. 258-265

[3] V. Kochkin, D. Erak, D. Makhotin "Modernization of existing VVER-1000 surveillance programs" in Journal of ASTM International article \#017204JAI, 2011

[4] Bukanov V.N., Diemokhin V.L., Grytsenko O.V., Vasylieva O.G., Pugach S.M. Comparison of Irradiation Conditions of VVER-1000 Reactor Pressure Vessel and Surveillance Specimens for Various Core Loadings // Reactor Dosimetry: State of the Art 2008 (Proc. 13th Intern. Symp. on Reactor Dosimetry, Hotel Akersloot, the Netherlands, 25-30 May 2008) - World Scientific, 2009. - P. 318-324

[5] Voloshchenko A. M., Gukov S. V., Russkov A. A., Gurevich M. I. e. a. The CNCSN-2: One, Twoand Three-Dimensional Coupled Neutral and Charged Particle Discrete Ordinates Code System // Proc. of Intern. Conf. on Advances in Mathematics, Computational Methods, and Reactor Physics. - Saratoga Springs, USA, May 3-7, 2009, on CD-ROM

[6] Andrei M. Voloschenko CONSISTENT P1 SYNTHETIC ACCELERATION SCHEME FOR TRANSPORT EQUATION IN 3D GEOMETRIES // Mathematics and Computation, Supercomputing, Reactor Physics and Nuclear and Biological Applications Palais des PapesAvignon, France, September 12-15, 2005, on CD-ROM, American Nuclear Society, LaGrange Park, IL (2005) 


$$
15^{\text {th }} \text { ISRD }
$$

[7] CNCSN 2009: One, Two- and Three-Dimensional Coupled Neutral and Charged Particle Discrete Ordinates Parallel Multi-Threaded Code System, RSICC code package CCC-726, 2009

[8] A. M. Voloschenko, "KATRIN-1.0: Three-Dimensional Multigroup Discrete-Ordinates Transport Code," Proc. Int. Conf. On the New Frontiers of Nuclear Technology: Reactor Physics, Safety and High-Performance Computing - PHYSOR 2002, Seoul, Korea, October 7-10, 2002

[9] Voloshchenko A.M KP1 acceleration scheme for inner iterations consistent with the weighted diamond differencing scheme for the transport equation in three-dimensional geometry. Computational Mathematics and Mathematical Physics. 2009. T. 49. No. 2. p. 334-362. ISSN: 0044-4669

[10] Averin A.V., Voloschenko A.M. Consistent P1 synthetic acceleration method for outer iterations // Transp. Theory and Statist. Phys. 1994. V. 23. No. 5. P. 701-730 